\title{
Mental Health Hospital Admissions: a Teachable Moment and Window of Opportunity To Promote Change in Drug and Alcohol Misuse
}

\author{
Hermine L. Graham ${ }^{1}$ - Alex Copello ${ }^{1,2}$ • \\ Emma Griffith $^{3}$ (D) Latoya Clarke ${ }^{1}$ - Kathryn Walsh ${ }^{1}$. \\ Amanda L. Baker ${ }^{4}$ Max Birchwood ${ }^{5}$
}

Published online: 26 February 2018

(C) The Author(s) 2018. This article is an open access publication

\begin{abstract}
Hospital admissions provide a "teachable moment". Many patients admitted to mental health hospitals have co-existing substance misuse. As acute symptoms decline, a window of increased insight into factors that contributed to becoming unwell and admission may present. This study used this "teachable" opportunity to assess the acceptability of delivering a brief integrated motivational intervention (BIMI) to inpatients and the feasibility of delivery by inpatient staff. Qualitative interviews were completed with 21 inpatients experiencing co-occurring schizophrenia-related or bipolar disorder diagnoses and substance misuse who received the BIMI. Twelve staff members completed either individual interviews or a focus group. Four themes were identified from the qualitative interviews with participants; these were openness/readiness to talk about substance use, feeling valued, understanding substance use and helpful skills and processes; each with a number of subthemes. Participants appeared to find the intervention useful; although, felt they did not always have the "headspace". One theme emerged from the staff data, the acceptability of the approach for inpatient ward staff, which had four subthemes; training in the intervention; delivering the intervention; joint working; and feasibility. Staff considered the targeted style of the BIMI useful. Delivery considerations included "timing" and competing ward duties. Hospital
\end{abstract}

Trial Registration: NIHR CRN/UKCRN: 13978 date of registration - 06.02.13; ISRCTN43548483 date of registration - 4/17/2014

Emma Griffith

e.j.griffith@bath.ac.uk

1 School of Psychology, University of Birmingham, Edgbaston, Birmingham B15 2TT, UK

2 Birmingham and Solihull Mental Health Foundation NHS Trust, Birmingham, UK

3 School of Psychology, University of Bath, Claverton Down, Bath BA2 7AY, UK

4 The University of Newcastle, Callaghan, NSW 2308, Australia

5 Division of Mental Health and Wellbeing, University of Warwick, Coventry CV4 7AL, UK 
admission presents a natural window of opportunity for staff to start conversations with inpatients about substance misuse.

Keywords Dual diagnosis · Inpatients · Qualitative research · Schizophrenia · Substance misuse

A hospital admission may represent a "teachable moment" for health-related behaviours (e.g. Lau et al. 2010; Buchbinder et al. 2014), that is, a time when health-related behaviours (e.g. substance use) that may have indirectly contributed to the admission potentially become more open to change. Individuals are in a health setting where they are "primed" to health and so more open to consider links between the issue that led to their hospitalisation and other healthrelated behaviours. There is a growing literature demonstrating the effectiveness of screening and brief interventions in general hospitals that seek to capitalise on this moment (e.g. Buchbinder et al. 2014; Cobain et al. 2011; Désy et al. 2010; Lai and Sitharthan 2012). A Cochrane review of 14 randomised controlled trials (RCTs) involving brief motivational interventions for alcohol use delivered during non-alcohol-related general hospital admissions concluded patients receiving brief interventions reduced their alcohol use more than control groups (McQueen et al. 2011). However, Buchbinder et al. (2014) found these "teachable moments" are often not recognised during hospital admissions and thus represent missed opportunities for interventions. More importantly, the effectiveness of utilising this "moment" during an acute psychiatric hospital admission has not been explored.

The literature suggests that $22-44 \%$ of mental health hospital admissions have co-existing substance misuse problems (DOH 2006). Substance misuse in individuals experiencing severe mental health problems is associated with low motivation to change alcohol and drug use (McHugo et al. 1995; Carey 1996; Swanson et al. 1999), increased mental health hospital admissions (DOH 2006), and poor engagement and outcomes for treatment (e.g. Mueser et al. 1992). It is recognised that poor treatment engagement represents a barrier for change and positive treatment outcomes (Swanson et al. 1999; Drake et al. 2001; Mueser 2003). The drug misuse mortality rate in 2015 was suggested to be "the highest ever recorded, at 43.8 deaths per million population" (Office for National Statistics 2016 p.3). When considering individuals who had contact with mental health services during the preceding 12 months, these individuals were highlighted to account for $28 \%(18,172)$ of deaths by suicide across the UK between 2004 and 2014, furthermore that 'over half the patients who died by suicide had a history of alcohol or drug misuse' (University of Manchester 2016, p. 9). Despite the high prevalence of this client group and the risks associated with being part of it for example violence (Fazelet et al. 2009) and lung disease (Sokal et al. 2004), there is currently no routine assessment of the role substance use plays in a psychiatric admission within the admission process (DOH 2006, Graham et al. 2016b). In recent years, the needs of this client group have received increasing focus in government policy; most recently a Public Health England (PHE) Guide (PHE 2017) which supports the Five Year Forward View for Mental Health (Mental Health Taskforce 2016) implementation (PHE 2017). This guidance highlights meeting the needs of this client group as "everyone's job" (PHE 2017 p.23).

A Cochrane Review including 32 RCTs of psychosocial interventions for severe mental health and substance use problems suggested "assessing brief interventions (such as motivational interviewing) over standard care will allow the identification of cost-effective and easy to implement components that can be quickly integrated into standard care" (Hunt et al. 2013 p.62). The evidence did not conclusively support any one psychosocial intervention (Hunt et al. 2013). When specifically focusing on inpatient settings, promising evidence 
appears to be suggested from studies conducted by Swanson et al. 1999, Baker et al. 2002, Kavanagh et al. 2004 and Bagøien et al. 2013. In terms of the Bagøien et al. (2013) study, the authors highlight that following the administration of two sessions of motivational interviewing in an emergency psychiatric inpatient unit setting, a reduction in the frequency of substance use was observed two years later. Motivational brief interventions appear to show lower substance use (Baker et al. 2002; Kavanagh et al. 2004; Bagøien et al. 2013) and superiority to treatment as usual (TAU) in terms of attendance at the first community appointment (Swanson et al. 1999).

To date, no published literature reviews were found that specifically focused on brief interventions for co-occurring mental health and problematic substance use. However, a recent, unpublished systematic review of the current literature (2006-2016; in psychinfo, medline, web of science) has considered the effectiveness of brief interventions for co-occurring mental health and substance use problems (Goulding 2016). From the 21 papers reviewed, the most common substances studied were alcohol (21) and cannabis (11). Mental health diagnoses included both common and severe mental health problems, the most prevalent being depression (8 studies). Of these, five studies were conducted in inpatient settings (Bagøien et al. 2013; Brown et al. 2015; Milner et al. 2009; Goti et al. 2010 and Graham et al. 2016b), three of which included adults (Bagøien et al. 2013; Graham et al. 2016b; Milner et al. 2009) and the remaining two adolescents (Brown et al. 2015; Goti et al. 2010). Of these five studies, four evaluated motivational interviewing interventions, one was the current study of the BIMI (which incorporated cognitive behavioural and motivational techniques) and the final study evaluated a standardised workbook (Milner et al. 2009). Four studies focused on alcohol and substance use (Brown et al. $2015 N=151$; Bagøien et al. $2013 N=135$; Graham et al. 2016a, b $N=59$; Goti et al. $2010 N=143$ ) and one on alcohol (Milner et al. $2009 N=87$ ). Overall, these studies evaluating brief interventions in inpatient settings suggest the evidence of the effectiveness for brief intervention for co-occurring mental and substance use problems to be promising; however, a number of methodological limitations were noted e.g. small sample size (e.g. Graham et al. 2016b). The review therefore suggests the need for robust trials with the provision of follow-up sessions after discharge from hospital (Goulding 2016).

An acute mental health hospital admission therefore could also represent a potential "teachable moment" when a brief intervention for substance misuse may be effective. That is, a natural window of opportunity for staff to engage psychiatric inpatients to explore behaviours that may be negatively impacting on their mental health, at a natural time of increased insight and reflection on the factors contributing to the admission (Rosenthal 2003; Blow et al. 2010). The question that required exploration was whether this is feasible in an acute mental health setting using the current intervention, which involved training existing routine inpatient staff to provide the BIMI. It is suggested that the BIMI is well placed to capitalise on the window of opportunity that the inpatient admission provides. This intervention also incorporated a booster session three months after the final BIMI session, which was envisaged to be completed jointly with the participant's community team to help consolidate the work completed and link to community services to facilitate the individual achieving their goals.

\section{Aims}

A randomised controlled feasibility trial was conducted to assess whether a mental health hospital admission represented a natural window of opportunity for inpatients who misuse 
alcohol or drugs to be offered a Brief Integrated Motivational Intervention (BIMI) for drug and alcohol misuse whilst on a ward (Graham et al. 2016b). The qualitative component is reported separately in this paper to allow an in-depth analysis of the following aims:

1. How acceptable is receiving a BIMI to mental health inpatients?

2. How acceptable and feasible is delivering a BIMI for inpatient staff?

3. What were the facilitators and the barriers to delivering a BIMI in a hospital setting?

\section{Method}

\section{Design}

The pilot feasibility study was an open (rater blinded), prospective randomised trial that analysed by intention to treat (as outlined in Graham et al. 2016b). The trial utilised concealed randomisation; blind, independent assessment of outcome at 3-months; characterisation of refusers and drop-outs. The participants included were randomised on a 1:1 basis, to one of two experimental conditions: BIMI in addition to Treatment As Usual (TAU); or TAU. The inclusion criteria were adults aged 18 years or above with an ICD-10 diagnosis of schizophrenia, schizoaffective or delusional disorders (F20,22,23,25,28,29); bipolar affective disorders (F31); or recurrent depressive disorder (F33.2), service users of community mental health services; new admissions within the acute phase of severe mental health problems; who were identified as misusing alcohol and/or drugs over the past month based on a minimum score of 3 (abuse/dependent use based on DSM-IV diagnostic criteria for substance-related disorders) on the Clinician Alcohol/Drugs Use Rating Scale over the past three months (Drake et al. 1996); and needed to have a care co-ordinator in a community mental health team. Capacity to consent for eligible participants was established by the responsible clinical officer. All participants were recruited from inpatient units, within a single UK, National Health Service (NHS) Trust offering a total of 202 beds over a 15-month period, which included 11 acute wards and three Psychiatric Intensive Care Units (PICUs; Graham et al. 2016b) .

\section{Randomisation}

The trial used independent central randomisation using a concealed process via e-mail. Researchers were blind to participant treatment group allocation until baseline; posttreatment and 3-month follow-up quantitative assessments had been completed. Researchers were unblinded once the 3-month data had been collected. Participants in the BIMI group and staff who delivered the BIMI then completed a qualitative interview. Of the 59 participants $(\mathrm{BIMI}=30, \mathrm{TAU}=29)$ who gave informed consent to participate in the feasibility RCT, 21 participants in the treatment group (BIMI plus treatment as usual) agreed to complete a semi-structured qualitative interview at the three-month follow-up point. See Graham et al. (2014, 2016b) for a full description of the wider study methodology. The trial was funded by the National Institute for Health ResearchResearch for Patient Benefit and received ethical approval from the West Midlands The Black Country National Research Ethics Committee (12WM/0369) and was registered with Current Controlled Trials (ISRCTN43584883). 


\section{Participants}

Eligible participants were identified by research staff based on review of care records. A screening measure was completed with Care Co-ordinators confirming trial eligibility. Within two weeks of admission, eligible participants were invited to participate (once acute symptoms eased). Written information about the study was provided and written consent obtained. Upon completion of a battery of assessments, participants were randomly allocated to the intervention BIMI group (in the context of TAU) or the TAU group (the control group). Just prior to the 3-month data, collection meetings were scheduled for completion of the follow-up assessment battery by blind researchers. Participants were not paid for study participation.

\section{Staff Sample}

Inpatient staff $(n=27)$ from 14 wards and specialist staff $(n=6)$ were trained to deliver the intervention; of these, 12 inpatient and 5 specialist staff delivered the BIMI; 12 of these staff took part in either individual qualitative interviews or a focus group.

\section{Brief Integrated Motivational Intervention (BIMI)}

A BIMI was delivered using a therapy manual designed for purpose (Graham et al. 2016a), as noted in Graham et al. (2016a, b); it is based on the initial two phases of cognitive-behavioural integrated treatment (C-BIT; Graham et al. 2004), techniques from cognitive therapy for substance use (Beck et al. 1993) and motivational approaches (Hettema et al. 2005). The BIMI provided a 3-step framework that promoted a collaborative conversational style discussion about substance use and its impact on mental health. The initial step provided participants with personalised feedback from a baseline assessment. This detailed participants' patterns of substance use and potential impacts on health and mental health in conjunction with discussion of individually tailored psychoeducational material about the substances used. The second step aimed to help participants make decisions about what outcomes they wanted and to build awareness of how substance use and mental health may interact and worsen each other. The third step encouraged participants to contemplate change and develop a change plan. Participants were offered a peer mentor during the second step of the intervention; however, this was only taken up by two participants.

The BIMI was delivered by specifically trained ward staff working jointly with staff from a specialist "dual diagnosis" service-wide service, the COMPASS Programme (Graham et al. 2003). The BIMI comprised of 4-6 and 15-30 min sessions provided over a 2 -week period, after the second week of admission and once the initial acute symptoms had subsided. The final session, a "booster", arranged for a months' time was provided by a member of the COMPASS Programme and attended by the participant's community-based Care Co-ordinator. It sought to help consolidate motivation, transfer the skills from the BIMI, and actively link participants with substance misuse treatment routinely integrated within community mental health teams. Staff were trained to provide the BIMI by two of the authors (HG and EG) over two days at the inpatient units, to ensure the location was convenient. The cost of the training was the time taken to provide the training by these professionals and staff being released to attend. 


\section{Treatment as Usual (TAU)}

Treatment as usual was "standard" ward care in line with inpatient trust policies which was regularly monitored by the UK Care Quality Commission.

\section{Data Collection}

\section{Procedure}

\section{Procedure and Analyses}

Qualitative interviews were completed with participants at the 3-month follow-up point by three Research Associates using a semi-structured interview schedule. For participants who received the intervention, a combination of recorded interviews or interview reports were used for analysis. This was done as some participants agreed to be interviewed but refused to be audio-recorded. A method of careful note-taking followed by detailed report writing was used for the latter cases. This method has been used successfully in previous research (e.g. Orford et al. 2005, 2006). Interviews sought to assess satisfaction with the treatment received and perceived processes of change, including helpful aspects of the therapeutic process and feedback on anything that could have been done differently.

A sample of therapists were interviewed after the 3-month follow-up point, using a semistructured interview, individually and in focus groups. Each interview and focus group was recorded, transcribed, or summarised and thematic analysis methods (Harding 2013; Braun and Clarke 2006) were used to analyse the transcripts. For both the participant and staff interviews and focus groups, a number of steps reflecting an iterative process and aiming to ensure reflexivity were followed. These included interviews being coded by at least two coders independently and consensus reached through group discussion; all interviews were coded by at least one coder who was not familiar with the contents of the intervention; saturation was reached through a staged approach to the analysis. Two in-patient participants were consulted on the final findings for the participant data analysis. Transcripts of a focus group attended by inpatient staff and individual interviews with inpatient staff and from the focus group with specialist staff from the COMPASS Programme and one individual interview were analysed using thematic analysis (Braun and Clarke 2006; Harding 2013).

\section{Results}

\section{Inpatient Participants' Demographics}

The demographic information for participants that were part of the focus group is shown in Table 1 and their exposure to the BIMI in Table 2.

\section{Staff Sample Demographics}

Table 3 highlights the demographic information for the two staff focus groups, one with trained inpatient staff $(n=3)$, one with COMPASS Programme staff $(n=4)$ and four individual 
Table 1 Participant baseline characteristics $(n=21)$

\begin{tabular}{|c|c|}
\hline & $\begin{array}{l}\text { MI } \\
(n=21)\end{array}$ \\
\hline \multicolumn{2}{|l|}{ Age } \\
\hline Mean (SD) & $38.5(\mathrm{SD} 9.33)$ \\
\hline \multicolumn{2}{|l|}{ Sex } \\
\hline Male & $18(85.7 \%)$ \\
\hline Female & $3(14.3 \%)$ \\
\hline \multicolumn{2}{|l|}{ Diagnosis } \\
\hline Schizophrenia $(\%)$ & $13(61.9)$ \\
\hline Schizoaffective disorder $(\%)$ & $3(14.3)$ \\
\hline Psychosis $(\%)$ & $0(0)$ \\
\hline Bipolar affective disorder (\%) & $5(23.8)$ \\
\hline \multicolumn{2}{|l|}{ Primary substance } \\
\hline Alcohol $(\%)$ & $9(42.86)$ \\
\hline Cannabis $(\%)$ & $9(42.86)$ \\
\hline Crack $(\%)$ & $0(0)$ \\
\hline Cocaine $(\%)$ & $0(0)$ \\
\hline Methadone $(\%)$ & $0(0)$ \\
\hline Legal highs (\%) & $2(9.5)$ \\
\hline Diamorphine $(\%)$ & $1(4.76)$ \\
\hline \multicolumn{2}{|l|}{ Ethnic origin } \\
\hline White British (\%) & $6(28.6)$ \\
\hline White Irish $(\%)$ & $2(9.5)$ \\
\hline Asian Indian (\%) & $0(0)$ \\
\hline Asian Pakistani (\%) & $2(9.5)$ \\
\hline Asian Bangladeshi (\%) & $0(0)$ \\
\hline Asian Other $(\%)$ & $0(0)$ \\
\hline Black Caribbean (\%) & $6(28.6)$ \\
\hline Black African (\%) & $0(0)$ \\
\hline Black Other $(\%)$ & $1(4.8)$ \\
\hline Mixed Caribbean (\%) & $4(19)$ \\
\hline Mixed African (\%) & $0(0)$ \\
\hline
\end{tabular}

interviews with inpatient staff and one COMPASS Programme Practitioner that were completed.

\section{Qualitative Evaluation}

\section{Inpatient Participants' Qualitative Interviews}

Four themes were identified from the qualitative interviews with participants; these were openness/readiness to talk about substance use, feeling valued, understanding substance use, and helpful skills and processes. A number of subthemes also emerged within each theme which will also be described in turn below:

Table 2 Exposure to the brief integrated motivational intervention (BIMI) for participants in the intervention group
Exposure to the BIMI

Mean number of sessions (sd)

$3.14(1.46)$

Range of number of sessions

$1-5$

Mean length of session in minutes (sd)

18.3 (4.90)

Mean total time receiving the interventions (sd) 
Table 3 Staff characteristics

\begin{tabular}{ll}
\hline Designation of staff trained to deliver the BIMI & Number of staff \\
\hline Mental health nurses & 4 \\
Staff nurse & 1 \\
Occupational therapists & 4 \\
Activity workers & 3 \\
Health care assistants & 2 \\
Gender of professionals trained & \\
$\quad$ Female & $85 \%$ \\
$\quad$ Male & $15 \%$ \\
\hline
\end{tabular}

Theme: Openness/readiness to talk about substance use

Within the theme of openness/readiness to talk about substance use, the following subthemes were identified:

Sub-theme: Being an Inpatient

Some participants said that the intervention provided an activity and someone to visit them on the unit whilst they were an inpatient as represented by a participant:

"It was interesting at the end of the day when I had different people come out to visit me.."

Being in a hospital environment, the structure and activities provided on the ward appeared to be a factor that influenced the openness and readiness of participants to make changes in their substance use. One participant said:

“...It gave me a lot of time to think because obviously while I was in hospital, I never touched cannabis for 7 weeks and I didn't need it because I was doing things and all that and they got me doing things and all of that whilst I was there".

Sub-theme: The Therapist's style

Therapist's communication style and the theoretical approach that underpinned the intervention appeared important in whether participants were open and chose to engage in the intervention;

"He never more or less told you it was bad for you or said that it was good for you or anything like that, but he left you to your, he just asked you certain questions and let you do the, the answering, you know what I mean";

Another participant described the staff delivering the intervention as "good listeners, understanding and compassionate". However, this contrasted with another participant who found the staff to be "childish" and the information given during the assessment feedback to be "irritating and not accurate".

Sub-theme: Timing 
The timing of the intervention appeared important in relation to the participant's current mental state and whether they had the cognitive capacity to be open to the intervention. One participant said he had "too much going on" with "being in hospital" to engage in the BIMI. Another that:

"I did feel like I could be open at that time but I did think that in view of other things that was going on, that may have been why it was a little bit unnecessary because it was like, I was having a lot of problems and to me that was the least of them at that time".

Sub-theme: Impact of current mental health on participant

Related to timing of the intervention and how participants' mental health influenced their openness to the intervention, one participant said that her mental health was not "stabilised" and therefore she "didn't want to do it". Another participant similarly said "I read them, but I couldn't study them, I couldn't study, my head was wasn't well".

Theme: Feeling valued/Nonspecific factors of the Intervention

Within the theme of feeling valued, the following sub-theme was identified:

Sub-theme: Someone giving time, 'going out of Their way'

Some participants described appreciating staff "going out of their way" to spend time talking with them:

"Erm, I suppose someone sitting there writing it down and talking about it with me is beneficial”.

Sub-theme: Generally helpful

A non-specific factor of the intervention that participants spoke about was finding the intervention generally helpful:

"Yeah, yeah definitely found it helpful... I'm definitely satisfied with it; it's made me look twice at things now",

With another saying they would recommend it to others:

"I think, you know, I think I'd recommend this to someone else I would".

Theme: Understanding substance use

Within the theme of understanding substance use, the following sub-themes were identified:

Sub-theme: Assessment feedback 
A number of participants found receiving feedback from their assessment helpful:

"It made me see what, what, erm, how much I was drinking as well, made me realise how much I was drinking and smoking".

However, another participant felt staff delivering the intervention were "naïve" and suggested that one of the inpatient staff members appeared "shocked" when feeding back the assessment information back and then commented on how much the participant was using. Another participant described the intervention as "scare monger[ing]", as she felt the information provided tried to "scare her into stopping taking legal highs".

Sub-theme: Psychoeducational information/Leaflets

Participants spoke about discovering new information in the psychoeducational information and leaflets that were provided; "I didn't know some of the stuff in them [the leaflets]"; this participant also added that the information helped him stop using because he "didn't need them problems".

Sub-theme: Worksheets and diagrams

Seeing the information about their substance use illustrated on worksheets appeared to remind some participants of the issues associated with their use, as expressed by one of the participants:

"We went through all the charts and the diagrams and it was good to be reminded of all the issues that I had faced the year before".

Theme: Helpful skills acquired during the intervention and research processes

Sub-theme: Pros and cons and decision-making

Having an opportunity to develop and reflect on the maintenance cycle of using alcohol or drugs and the impact of this on mental health enabled some participants to become increasingly more aware of this. Additionally, this also aided the decisionmaking and reflection and the pros and cons of their use, as illustrated by the following quote:

"It highlighted the fact that it was a cycle that I would be going through and that it would always, it may feel good at the time but it will always come back around and erm cause me issues in my mental health...It highlighted to me how much it costs a month, erm, I suppose the pros and cons...I suppose having people highlighting it to me increases the impact it has on my decision making";

Sub-theme: Coping strategies/techniques 
Some participants recalled specific coping strategies that were offered as part of the intervention as most helpful, such as strategies focussed on cravings and voices, as illustrated by the following quote:

"All I can really remember from it was some of the coping strategies, he taught me about like er ways to deal with cravings and stuff", "It was about, basically about how to side track my mind off cannabis onto something else really"...

One participant gave the example of discussing the ways to cope with hearing "voices and how to get distracted from them" and spoke about finding he could generalise this strategy to other situations and found he was "able to cope and relax when stressed" through using the breathing and relaxation techniques.

The goal planning worksheet appeared to serve as an opportunity for participants to have a sense of progressing toward their goals:

"I feel as if I'm getting somewhere because it's been building up yeah I feel as though I've been getting somewhere with some of them".

\section{Sub-theme: Research Processes}

The meetings with Research Associates at the data collection points were highlighted as a time when participants felt able to reflect on their substance use. One participant noted speaking to the researcher about his reasons for using and "getting it out" as a motivator. He said that he "just needed to explain it to someone" and for someone to listen so that he could "get it straight in my head"; and then when it was straight in his head he could stop using.

\section{Staff Sample Qualitative Interviews and Focus Groups}

The theme that emerged from this data focused on the Acceptability of the approach for inpatient ward staff; the subthemes within this were as follows: training in the intervention, delivering the intervention, joint working, and feasibility.

Sub-theme: Training in the intervention

Inpatient staff described the content of the training as "...all there" finding the "step-by step teaching style good" and the "role plays helpful". They liked learning how to speak to inpatients using a motivational style, however wanted more opportunities to practice this during the training and for the training to be longer;

“The training wasn't enough for you to feel confident to deliver that on your own, not for me anyway".

The duration and timing of the training were also highlighted:

"The length of time we were given to learn it and sort of internalise it didn't seem to be enough";

"I think when you're not doing it all the time you could do with a bit of training in between". 
With the gap between inpatient staff receiving training and then delivering the intervention noted as important:

"I think it was like 6 weeks later or something by the time I did the first intervention and by then your confidence for actually delivering it has dropped".

It appeared to be helpful to train with other staff on the inpatient unit as "... we kind of had to like refresh each other."

Furthermore, having a personal copy of the BIMI treatment manual was experienced as helpful by the inpatient staff:

"Before the session I'd have a quick look to see exactly what it was that we could be doing. That again is only a matter of refreshing, which was useful".

With other staff noting not always having time to read relevant sections of the manual prior to sessions;

"Once you had started you haven't got time to sit there and go over it again. I'd just have someone there from COMPASS and I'd discuss it with them instead".

Sub-theme: Delivering the intervention

Staff described some participants' mental health symptomatology impacting their capacity to engage:

"Some people are just not going to be in the right headspace and well enough to actually participate".

Some staff noted that participants' mental state/engagement fluctuated:

"You can go through two sessions with one and it went really well then he declined quite significantly."

However, they also found participants could be interested and open to intervention:

"We gave him the sheets and some information and he actually went away and thought about it and said "actually yeah I didn't see it like that, but actually I could do this with that money".

Staff described some variability in engagement, with some participants engaged well and received a number of sessions and there being a sense of disappointment when they were unable to continue the intervention as participants were discharged or transferred quite quickly, related to their not knowing the outcomes for those participants:

“Then quite a few sort of got transferred so we didn't get any feedback of if they was offered any sessions in like, when they moved around the trust".

Engagement in the intervention appeared to be influenced by a number of factors, including the inpatients' mental state. Staff identified that some participants were happy to engage and said "the way that the patients responded to it was sometimes surprisingly good", whilst others did not remember consenting to the research project; 
"You know they say I don’t know nothing about that Miss and I don’t remember signing up for it".

The way in which the assessment feedback was given was suggested to impact on engagement. Staff said reading the assessment sheet to the client was not as effective as sharing it in a conversational style. Furthermore, for some participants, there was greater engagement when staff were familiar:

"The person felt quite relaxed speaking with somebody that they already know".

The length of sessions was noted by some staff as a positive factor that also worked well in a ward environment:

"The brevity of the session was very good, that was useful, especially on an inpatient environment because things change so much that you've only got a short amount of time to allocate".

and that "...because the use of psychological therapies aren't appreciated on the ward anyway so it was good to see that happen..."

Inpatient staff described liking as having a new approach to talk about substance use with inpatients, including the motivational style, that enabled them to focus away from reasons not to use and instead to provide participants with a different way of looking at it:

"It was good the way you put it to them, you put it to them and they actually came back to you and said "well I'd like to give up", rather than you saying to them".

Staff described the intervention as seeming to start a process "... it prepares them doesn't it, going out into the community and getting support in the community they have already started the support on the ward".

Sub-theme: Joint working

Inpatient staff described a number of benefits of joint working with other trained ward staff, including reassurance, support, and collaboration; "I had to do one on me own which I found quite difficult". Also, noting the benefits of providing the intervention jointly with a specialist COMPASS Programme worker appeared to contribute to them feeling "reassured working with an expert" and finding it more difficult to provide the intervention without them, as illustrated by the following quote:

"I was fine when I was with [COMPASS Worker] but when I had to do it on my own I got a bit nervous and I found it quite difficult".

However, joint working was also noted to come with some frustrations, as staff suggested it was at times difficult to co-ordinate joint sessions with the community-based COMPASS Programme clinicians and some staff also described finding themselves unable to build their own confidence, as illustrated by this staff member:

"....you needed the guidance of the COMPASS worker and let them take the lead more than I did, which I found was frustrating in a way because I didn't feel like I ever built the confidence up to take the lead in the session really..." 
Sub-theme: Feasibility

Inpatient staff described feeling positive about delivering a therapeutic intervention that differed from their traditional ward role and felt it was "nice to deliver something small but structured". Some staff described being less keen on the approach as it was more formalised and structured:

"...Yeah it was much more formalised whereas on the ward you'd have those conversations and pop in and out when you're getting to know people so less pressure to talk about it..."

With another staff member questioning whether they would engage the client in a way that allowed them to reflect on their use when doing this more informally:

“...this is what I found quite effective really, the first part of the session as I remember, is sort of eliciting from the patient what they found beneficial about the substance that they are using. and that's something that you wouldn't really do even in informal chats, what's good about it, tell me what's good about it, and that's what you can see quite quickly that engages them, but it allows them to begin to question their own motives...."

Inpatient staff described a conflict of roles at times when delivering the intervention:

"To just be off the ward whilst things were going on it feels almost like a conflict of interest in a way",

With their job role and tasks on the ward seen to conflict with their role as a therapist delivering the intervention:

"Your priority isn't a research project that you've been asked to take part in, its what's going on on the ward on that day."

The changeable and at times chaotic nature of the ward environment appeared to contribute to their perceived capacity to deliver the intervention:

"One of the sessions there was someone kicking off outside of the door and I was torn between staying here and getting out and dealing with that."

In terms of location, staff noted that if the intervention was delivered in a location away from the ward, this was a different experience:

"If it's off the ward and you're allocated the time then it's a different kettle of fish, because you're off the ward you're not expected to rush".

Staff described a philosophical difference between the standard treatment model on inpatient units and that underpinning the BIMI:

“On the ward you've got psychiatric models not psychological models, so you haven't got a formal psychological model to give, so that's being exposed to a different modality, certainly a different form of treatment."

However, in general, inpatient staff appreciated using a psychological approach:

"I quite liked it really, because the use of psychological therapies aren't appreciated on the ward anyway so it was good to see that happen, and the way that the patients 
responded to it was sometimes surprisingly good, so I could see how it got people thinking a bit"

With staff noticing that the intervention appeared to change inpatients' perception of discussing substance use with inpatient staff:

"Client's feel they can talk openly to me now".

\section{Discussion}

Training staff to use the BIMI, as part of their routine inpatient work, was an attempt to utilise the "window of opportunity" to engage inpatients in structured discussions about their substance misuse. Overall, the qualitative data suggests that inpatients and staff found the BIMI both feasible and acceptable when delivered on inpatient wards.

A number of important factors appeared to emerge from the data that suggested that the BIMI was acceptable to inpatients. Participants perceived some non-specific factors as helpful, such as staff giving time, and an open, non-judgemental, compassionate, accurate communication style in delivering the intervention appeared to promote greater reflection and engagement. Some specific factors of the BIMI, such as the personalised assessment feedback, enabled participants to reflect on the amount of substances they were using, focussing on the perceived "benefits", harms/costs, and impact on mental health associated with their use, as well as developing new coping strategies and techniques that appeared to promote motivation and change. However, a number of barriers to delivering the BIMI also emerged; the timing of the intervention was a common theme between staff and participants, including a participant not feeling they had enough mental "headspace" to engage in discussions about their substance use.

The second aim was to assess the acceptability and feasibility of routine inpatient staff working on acute mental health hospital wards delivering a brief intervention. A number of factors appeared to emerge; trained inpatient and specialist staff felt the motivational style and the brevity of the sessions were helpful in engaging inpatients in discussions about their substance use. Inpatient staff described the support and collaboration offered by delivering the intervention with another trained member of staff helpful; co-facilitation with a specialist practitioner added an additional layer of expertise and a prompt to deliver the intervention, although at times it was practically challenging to organise. Timing appeared important; the fluctuating inpatient's mental health at times impacted the inpatients' consistency of mind, presentation, and willingness to engage. Communication was suggested as a barrier which influenced ease of joint working with a specialist practitioner. If inpatient staff adopted a directive, judgemental style of communication in therapeutic interactions with participants appeared to increase disengagement. Trained inpatient staff reported that at times the intervention conflicted with nursing duties and, the more, medical philosophy of the ward.

\section{Limitations and Relevance for Clinical Practice}

Potential limitations of delivering a brief intervention in an acute psychiatric setting that focuses on substance use and its impact on mental health are important to consider. These 
include staff time and availability, uptake of the training, and philosophy change. Additionally, it did emerge that sometimes some inpatients were not cognitively able to engage in such an intervention. In many acute mental health hospitalizations, a number of crises may need to be addressed more immediately including the risk to others and self and acute psychotic symptoms. Nonetheless, the key role that alcohol and drug misuse play in risk and engagement in risky behaviours means that to be able to address substance use problems at this point may likely be a risk reducing strategy; especially given the relationship between substance use and risk outlined in the introduction, making this something that warrants further exploration. The potential bias in a small number of the participants agreeing to participate in the qualitative interviews is important to note.

The qualitative findings underscore changes in clinical practice that would be necessary on wards to enable a brief intervention to become part of standard clinical practice on wards (Baker et al. 2002; Fahy et al. 2011). These would need to include strategic decisions in the management, philosophy, and priorities of a ward for staff and inpatients to perceive therapeutic interventions as central to an inpatient admission. Such changes could herald a shift in the focus of treatment during a mental health admission from "containment" and "management" to providing "protected time" where it is perceived as a "therapeutic window of opportunity" and "teachable moment" (Stenhouse 2011; Thomson and Hamilton 2012; Butler et al. 2014).

The low number of participants included in the study and able to be interviewed is important to acknowledge. However, this pilot study was conducted within the context of a feasibility RCT and represented the first stage in the process to carry out a definitive RCT. The potential utility of this approach being used in a community setting is acknowledged; however, the need for this to be rigorously evaluated is also noted.

\section{Conclusion and Future Directions}

An inpatient admission to a mental health inpatient unit does appear to present a teachable moment for inpatients, who have some degree of mental stability, and a window of opportunity for inpatient staff to start a conversation about substance misuse. The findings indicate that it is both feasible and acceptable for inpatient staff to engage inpatients in short burst discussions about their substance misuse whilst admitted to psychiatric hospitals as has been found in general and Emergency Department settings (Lau et al. 2010; Buchbinder et al. 2014). A definitive RCT is needed to establish the effectiveness and cost-effectiveness of this brief intervention to increase engagement in treatment and to reduce substance misuse, repeat hospitalisations, and risk.

Acknowledgements This study is funded by the National Institute for Health Research (NIHR) Research for Patient Benefit Programme: PB-PG-1010-23138. It was sponsored by Birmingham \& Solihull Mental Health NHS Foundation Trust and the University of Birmingham. This manuscript presents independent research funded by the National Institute for Health Research (NIHR) under its Research for Patient Benefit (RfPB) Programme (number PB-PG-1010-23138). The views expressed are those of the author (s) and not necessarily those of the NHS, the NIHR, or the Department of Health. Professor Birchwood was partially funded by the NIHR through the Collaborations for Leadership in Applied Health Research and Care for the West Midlands (CLAHRC-WM). Special thanks go to all the community and inpatient staff and service users in BSMHFT for their support and involvement. We also appreciate the input of Professor Liz Hughes and Josh Goulding. 
Compliance with Ethical Standards All procedures followed were in accordance with the ethical standards of the responsible committee on human experimentation (institutional and national) and with the Helsinki Declaration of 1975, as revised in 2000 (5). Informed consent was obtained from all patients for being included in the study.

Conflict of interest All authors declare that they have no conflicts of interest.

Open Access This article is distributed under the terms of the Creative Commons Attribution 4.0 International License (http://creativecommons.org/licenses/by/4.0/), which permits unrestricted use, distribution, and reproduction in any medium, provided you give appropriate credit to the original author(s) and the source, provide a link to the Creative Commons license, and indicate if changes were made.

\section{References}

Baker, A., Lewin, T., Reichler, H., Clancy, R., Carr, V., Garrett, R., et al. (2002). Evaluation of a motivational interview for substance use within psychiatric in-patient services. Addiction, 97(10), 1329-1337.

Beck, A. T., Wright, F. D., Newman, C. F., \& Liese, B. S. (1993). Cognitive therapy of substance abuse (p. 35). New York: Guilford Publications.

Blow, F. C., Walton, M. A., Murray, R., Cunningham, R. M., Chermack, S. T., Barry, K. L., et al. (2010). Intervention attendance among emergency department patients with alcohol and drug-use disorders. Journal of Studies on Alcohol and Drugs, 71, 713-719.

Braun, V., \& Clarke, V. (2006). Using thematic analysis in psychology. Qualitative Research in Psychology, 3(2), 77-101.

Brown, R. A., Abrantes, A. M., Minami, H., Prince, M. A., Bloom, E. L., Apodaca, T. R., Strong, D. R., Picotte, D. M., Monti, P. M., MacPherson, L., Matsko, S. V., \& Hunt, J. I. (2015). Motivational interviewing to reduce substance use in adolescents with psychiatric comorbidity. Journal of Substance Abuse Treatment, 59, 20-29.

Bagøien, G., Bjørngaard, J. H., Østensen, C., Reitan, S. K., Romundstad, P., \& Morken, G. (2013). The effects of motivational interviewing on patients with comorbid substance use admitted to a psychiatric emergency unit - a randomised controlled trial with two year follow-up. BMC Psychiatry, 13(1), 93.

Buchbinder, M., Wilbur, R., Zuskov, D., Mclean, S., \& Sleath, B. (2014). Teachable moments and missed opportunities for smoking cessation counselling in a hospital emergency department: a mixed-methods study of patient-provider communication. BMC Health Services Research, 14, 651.

Butler, M. P., Begley, M., Parahoo, K., \& Finn, S. (2014). Getting psychosocial interventions into mental health nursing practice: a survey of skill use and perceived benefits to service users. Journal of Advanced Nursing, $70(4), 866-877$.

Carey, K. B. (1996). Substance use reduction in the context of outpatient psychiatric treatment: a collaborative, motivational, harm reduction approach. Community Mental Health Journal, 32, 291-306.

Cobain, K., Owens, L., Kolamunnage-Donar, Fitzgerald, R., Gilmore, I., \& Pirmohamed, M. (2011). Brief interventions in dependent drinkers: a comparative prospective analysis in two hospitals. Alcohol, 46(4), $434-440$.

Désy, P. M., Howard, P. K., Perhats, C., \& Li, S. (2010). Alcohol screening, brief intervention, and referral to treatment conducted by emergency nurses: an impact evaluation. Journal of Emergency Nursing, 36(6), $538-545$.

DOH. (2006). Dual diagnosis in mental health inpatient and day hospital settings. UK: DOH.

Drake, R. E., Mueser K. T., \& McHugo, G. J. (1996). Clinician rating scales: Alcohol Use Scale (AUS), Drug Use (DUS), and Substance Abuse Treatment Scale (SATS). In L. I. Sederer, \& B. Dickey (Eds.), Outcome assessment in clinical practice (pp. 113-116). Baltimore: Williams \& Wilkins.

Drake, R. E., Essock, S. M., Shaner, A., Carey, K. B., Minkoff, K., Kola, L., et al. (2001). Implementing dual diagnosis services for clients with severe mental illness. Psychiatric Services, 52, 469-476.

Fahy, P., Croton, G., \& Voogt, S. (2011). Embedding routine alcohol screening and brief interventions in a rural general hospital. Drug and Alcohol Review, 30(1), 47-54.

Fazelet, S., Gautam, G., Linsell, L., Geddes, J. R., \& Grann, M. (2009). Schizophrenia and violence: systematic review and meta-analysis. PLoS Medicine, 6(8), e1000120. https://doi.org/10.1371/journal.pmed.1000120.

Goti, J., Diaz, R., Serrano, L., Gonzalez, L., Calvo, R., Gual, A., \& Castro, J. (2010). Brief intervention in substance-use among adolescent psychiatric patients: a randomized controlled trial. European Child \& Adolescent Psychiatry, 19(6), 503-511. https://doi.org/10.1007/s00787-009-0060-5.

Goulding, J. (2016). Effectiveness of brief interventions in comorbid substance use and mental illness. Unpublished Masters (dissertation). Birmingham: University of Birmingham. 
Graham, H. L., Copello, A., Birchwood, M. J., Maslin, J., McGovern, D., Orford, J., \& Georgiou, G. (2003). The combined psychosis and substance use (COMPASS) programme: an integrated shared-care approach. In H. L. Graham, A. Copello, M. J. Birchwood, \& K. T. Mueser (Eds.), Substance misuse in psychosis: approaches to treatment and service delivery. Chichester: Wiley.

Graham, H. L., Copello, A., Birchwood, M. J., et al. (2004). Cognitive behavioural integrated treatment (CBIT): a treatment manual for substance misuse in people with severe mental health problems. Chichester: Wiley.

Graham, H. L., Birchwood, M., Griffith, E., et al. (2014). A pilot study to assess the feasibility and impact of a brief motivational intervention on problem drug and alcohol use in adult mental health inpatient units: study protocol for a randomized controlled trial. Trials, 15, 308.

Graham, H. L., Copello, A., Birchwood, M., \& Griffith, E. (2016a). Brief integrated motivational intervention: a treatment manual for co-occurring mental health and substance use problems. Chichester: Wiley.

Graham, H. L., Copello, A., Griffith, E., et al. (2016b). Pilot randomised trial of a brief intervention for co-morbid substance misuse in psychiatric inpatient settings. Acta Psychiatrica Scandinavica, 133(4), 298-309.

Harding, J. (2013). Qualitative data analysis from start to finish. London: SAGE.

Hettema, J., Steele, J., \& Miller, W. R. (2005). Motivational interviewing. Annual Review of Clinical Psychology, 2005(1), 91-111.

Hunt, G. E., Siegfried, N., Morley, K., Sitharthan, T., \& Cleary, M. (2013). Psychosocial interventions for people with both severe mental illness and substance misuse. Cochrane Database of Systematic Reviews (10): CD001088. https://doi.org/10.1002/14651858.CD001088.pub3.

Kavanagh, D. J., Young, R., White, A., Saunders, J. B., Wallis, J., Shockley, N., et al. (2004). A brief motivational intervention for substance misuse in recent-onset psychosis. Drug and Alcohol Review., 23(20), 151-155.

Lai, H. M., \& Sitharthan, T. (2012). Comparison of inpatients with comorbid mental health disorders and alcoholand other-substance-use disorders within general hospitals and psychiatric hospitals in NSW, Australia. Journal of Substance Use, 17(3), 301-309.

Lau, K., Freyer-Adam, J., Gaertner, B., Rumpf, H. J., John, U., \& Hapke, U. (2010). Motivation to change risky drinking and motivation to seek help for alcohol risk drinking among general hospital inpatients with problem drinking and alcohol-related diseases. General Hospital Psychiatry, 32(1), 86-93.

McHugo, G. J., Drake, R. E., Burton, H. L., \& Ackerson, T. H. (1995). A scale for assessing the stage of substance abuse treatment in persons with severe mental illness. Journal of Nervous and Mental Disorders, $183,762-767$

McQueen, J., Howe, T. E., Allan, L., Mains, D. \& Hardy, V. (2011). Brief interventions for heavy alcohol users admitted to general hospital wards. Cochrane Database of Systematic Reviews. (8): CD005191. https://doi. org/10.1002/14651858.CD005191.pub3McQueen.

Mental Health Taskforce. (2016). The five year forward view for mental health. England: Mental Health Taskforce.

Milner, K. K., Barry, K. L., Blow, F. C., \& Welsh, D. (2009). Brief interventions for patients presenting to the psychiatric emergency service (PES) with major mental illnesses and at-risk drinking. Community Mental Health Journal, 46(2), 149-155.

Mueser, K. T. (2003). Integrated service delivery models. In H. L. Graham, A. Copello, M. J. Birchwood, \& K. T. Mueser (Eds.), Substance misuse in psychosis: approaches to treatment \& service delivery (pp. 93-105). Chichester: Wiley \& Sons.

Mueser, K. T., Bellack, A. S., \& Blanchard, J. J. (1992). Co-morbidity of schizophrenia and substance abuse: implications for treatment. Journal of Consulting and Clinical Psychology, 60, 845-856.

Office of National Statistic. (2016). Deaths related to drug poisoning in England and Wales: 2015 registrations: deaths related to drug poisoning in England and Wales from 1993 onwards, by cause of death, sex, age and substances involved in the death. Newport: National Office of Statistics.

Orford, J., Hodgson, R., Copello, A., John, B., Smith, M., Black, R., et al. (2005). On behalf of the UKATT research team. The client's perspective on change during treatment for an alcohol problem: qualitative analysis of follow-up interviews in the UK alcohol treatment trial. Addiction, 101, 60-68.

Orford, J., Kerr, C., Copello, A., Hodgson, R., Alwyn, T., Black, R., et al. (2006). Why people enter treatment for alcohol problems: findings from UKATT pre-treatment interviews. Journal of Substance Use, 11(3), 161-176.

Public Health England. (2017). Better care for people with co-occurring mental health and alcohol/drug use conditions: a guide for commissioners and service providers. London: Crown Copyright.

Rosenthal, R. N. (2003). An inpatient-based service model. In H. L. Graham, A. Copello, M. J. Birchwood, \& K. T. Mueser (Eds.), Substance misuse in psychosis: approaches to treatment and service delivery. Chichester: Wiley.

Sokal, J., Messias, E., Dickerson, F. B., Kreyenbuhl, J., Brown, C. H., Goldberg, R. W., \& Dixon, L. B. (2004). Comorbidity of medical illnesses among adults with serious mental illness who are receiving community psychiatric services. Journal of Nervous \& Mental Disease., 192(6), 421-427. 
Stenhouse, J. (2011). They all said you could come and speak to us': patients' expectations and experiences of help on an acute psychiatric inpatient ward. Journal of Psychiatric and Mental Health Nursing, 8(1), 74-80.

Swanson, A. J., Pantalon, M. V., \& Cohen, K. R. (1999). Motivational interviewing \& treatment adherence among psychiatric and dually diagnosed patients. Journal of Nervous and Mental Disease, 187, 630-635.

Thomson, L. D. A., \& Hamilton, R. (2012). Attitudes of mental health staff to protected therapeutic time in adult psychiatric wards. Journal of Psychiatric and Mental Health Nursing, 19, 911-915.

University of Manchester. (2016). National confidential enquiry into suicide and homicide in people with mental illness. Annual report and 20 year review 2016. Manchester: University of Manchester. 